\title{
Investigating the potential benefits of a new artificial tear formulation combining two polymers
}

This article was published in the following Dove Press journal:

Clinical Ophthalmology

12 September 2017

Number of times this article has been viewed

\author{
Peter A Simmons \\ Joseph G Vehige \\ Allergan plc, Irvine, CA, USA
}

Correspondence: Peter A Simmons Allergan plc, 2525 Dupont Drive, Irvine, CA 926I2, USA

$\mathrm{Tel}+\mathrm{I} 7142465514$

Fax + I 7|47969388

Email Simmons_Peter@allergan.com
Purpose: Artificial tear formulations typically contain a water-soluble polymer to enhance residence time, moisture retention, and binding to the mucin coat of the ocular surface, which facilitate corneal healing. This study investigated the potential advantages of combining carboxymethylcellulose (CMC) and hyaluronic acid (HA) polymers in a single formulation.

Materials and methods: Individual CMC and HA solutions were prepared and tested for bulk viscosity in comparison to a solution that combined CMC and HA. Rheometry determined the differences between solutions at increasing shear rates, simulating eye movement and blinking.

Results: The bulk viscosity of the individual $0.5 \% \mathrm{CMC}$ and $0.1 \%$ HA solutions was 2.5 and $5.7 \mathrm{cP}$, respectively. The viscosity of the combined solution $(13.1 \mathrm{cP})$ was $60 \%$ higher than predicted by additive effects. Rheometry revealed shear rates between 10/second (open eye) and 10,000/second (blinking eye). At these rates, viscosity ranged from 2.7 to $3.5 \mathrm{cP}$ for $0.5 \%$ $\mathrm{CMC}, 2.8$ to $6.8 \mathrm{cP}$ for $0.1 \% \mathrm{HA}$, and 5.2 to $15.3 \mathrm{cP}$ for the $0.5 \% \mathrm{CMC}-0.1 \% \mathrm{HA}$ combination. Low-shear viscosity of the CMC-HA combination increased $48 \%$ over the sum of the individual solutions, but high-shear viscosity remained virtually unchanged. Data from CMC and HA solutions at higher concentrations were consistent with these results.

Conclusion: Combining CMC and HA polymers produced a synergistic increase in lowshear viscosity (which cannot be fully explained by simple molecular entanglement), while the high-shear viscoelasticity of the combined solution remained unaffected. These data suggest that CMC-HA combinations have properties that may be used to formulate artificial tears that optimize ocular retention (through higher low-shear viscosity), while minimizing blur and stickiness during blinking (through lower high-shear viscosity).

Keywords: artificial tear, eyedrop, dry eye, carboxymethylcellulose, hyaluronic acid

\section{Introduction}

Dry eye disease is a common ocular condition that has a high impact on the quality of life of affected patients, owing to discomfort and/or visual disability. ${ }^{1}$ It is a multifactorial disease associated with tear film hyperosmolarity and inflammation of the ocular surface, which can cause mild to incapacitating symptoms, such as itching, burning, blurred vision, mucous discharge, and photophobia. ${ }^{1-3}$

Artificial tear solutions are the mainstay of care for patients with mild dry eye symptoms, providing relief that can minimize corneal damage. Unpreserved formulations (which reduce the risk of developing preservative-associated side effects) are also often used concomitantly with prescribed therapies in patients with moderate to severe disease. $^{3-5}$ Artificial tear formulations typically contain a water-soluble polymer ${ }^{6}$ to provide enhanced residence time, retention of moisture, and binding to the mucin coat 
A
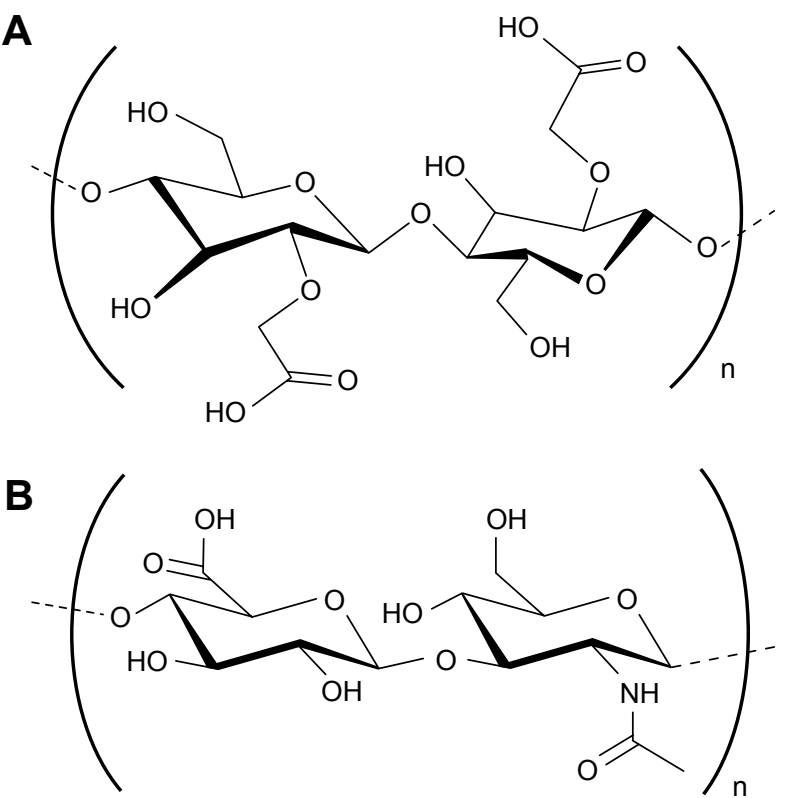

Figure I Structure of CMC and HA.

Notes: (A) In solution, CMC forms a relatively short linear polymer ( $\sim 400$ ); (B) compared with CMC, HA is a much longer polymer $(n>5,000)$ that forms a random, globular coil in solution, rather than being linear.

Abbreviations: CMC, carboxymethylcellulose; HA, hyaluronic acid.

of the ocular surface, which facilitate corneal healing. Carboxymethylcellulose (CMC; also known as carmellose) ${ }^{7}$ is a polymer (Figure 1A) that has been used as an active ingredient in artificial tear solutions for many years. ${ }^{8}$ Its clinical efficacy, binding capacity to ocular surface cells, and enhancement of corneal wound healing have been demonstrated in various model systems. ${ }^{7,9-17}$ Hyaluronic acid (HA), also a polymer (Figure 1B), is used as an artificial tear ingredient because of its favorable hydrating, viscoelastic, and wound-healing properties. ${ }^{5,18-27}$ These polymers, available in a range of molecular weights representing varying chain lengths, are generally dissolved in a dilute aqueous solution for use as a lubricant eyedrop, along with appropriate excipients, such as buffers, tonicity agents, and preservatives.

Given the distinct biochemical, biophysical, and therapeutic properties of CMC and HA, we investigated combining them in a single artificial tear formulation. We compared the properties of a formulation containing both $\mathrm{CMC}$ and $\mathrm{HA}$ with those of each polymer individually, focusing on viscosity because it can increase retention time, hence improving moisture retention and clinical outcomes. ${ }^{13}$ Multiple combinations were assessed based on concentrations of the polymers, with the goal of selecting formulas for subsequent clinical development.

\section{Materials and methods}

Solutions containing $0.5 \%$ or $1.0 \%$ CMC (low-viscosity type, approximately $90 \mathrm{kDa}$; Ashland Specialty Ingredients,
Wilmington, DE, USA), $0.1 \%, 0.15 \%$, or $0.25 \%$ HA (high molecular weight, $>1,000 \mathrm{kDa}$; HTL Biotechnology, Javené, France), plus the combinations $0.5 \% \mathrm{CMC}+0.1 \% \mathrm{HA}$, $0.5 \% \mathrm{CMC}+0.15 \% \mathrm{HA}$, or $1.0 \% \mathrm{CMC}+0.25 \% \mathrm{HA}$ were prepared in phosphate-buffered saline or a buffered solution (pH 7.2) containing glycerin, sodium borate, boric acid, sodium citrate, erythritol, L-carnitine, $\mathrm{KCl}, \mathrm{MgCl}_{2}, \mathrm{CaCl}_{2}$, and stabilized oxychloro complex (Purite) as a preservative (similar to marketed artificial tear formulations). The solubilization process involved standard pharmaceutical methods. Briefly, buffers and tonicity agents were dissolved at moderate temperatures $\left(40^{\circ} \mathrm{C}-50^{\circ} \mathrm{C}\right)$, and the polymers were added sequentially with rapid and sustained mixing to ensure complete dissolution. A combination of heat and filter sterilization techniques were then utilized to prepare final solutions for testing or clinical use.

The viscoelastic properties of each solution were assessed at low (10/second) and high (10,000/second) shear rates (to simulate eye movement and blinking, respectively) using a programmable rheometer (AR2000; TA Instruments, New Castle, DE, USA). Measurements were taken every 60 seconds using plate and cone geometry $\left(5^{\circ}\right.$ angle, $60 \mathrm{~mm}$ steel cone). CMC and HA solutions were also tested for bulk viscosity at a fixed shear rate (60 rpm, or approximately 79.2/second) using a Brookfield viscometer and SC4-18 spindle (Brookfield Engineering, Middleboro, MA, USA), and compared with formulations combining both $\mathrm{CMC}$ and $\mathrm{HA}$. All measurements were performed at $25^{\circ} \mathrm{C}$ in $\geq 3$ replicates.

\section{Results}

$\mathrm{CMC}$ and HA polymers both exhibited shear thinning (ie, viscoelastic behavior) under shear strain when analyzed individually on the rheometer. Although each polymer exhibited a characteristic curve owing to its specific molecular properties, viscosity at a given shear rate was affected by polymer concentration in both cases (Figure 2). For CMC $0.5 \%$ and $1.0 \%$, viscosity varied from $3.5 \mathrm{cP}$ (at 10/second) to $2.7 \mathrm{cP}$ (at $10,000 /$ second) and $5.8 \mathrm{cP}$ (at 10/second) to $4.7 \mathrm{cP}$ (at 10,000/second), respectively. For HA $0.1 \%, 0.15 \%$, and $0.25 \%$, viscosity at the same two shear rates were 6.8 and $2.8 \mathrm{cP}, 14.4$ and $3.4 \mathrm{cP}$, and 47.6 and $5.2 \mathrm{cP}$, respectively.

In a rheological analysis of combinations of $\mathrm{CMC}$ and HA polymers at $0.5 \%+0.1 \%, 0.5 \%+0.15 \%$, and $1.0 \%+0.25 \%$, viscosity varied from $15.3 \mathrm{cP}$ (at 10/second) to $5.2 \mathrm{cP}$ (at $10,000 / \mathrm{second}$ ), $25.0 \mathrm{cP}$ (at 10/second) to $5.8 \mathrm{cP}$ (at $10,000 /$ second), and $127.5 \mathrm{cP}$ (at $10 /$ second) to $11.9 \mathrm{cP}$ (at 10,000/second), respectively. Low (Figure 2A), medium (Figure 2B), and high (Figure 2C) concentrations of CMC 

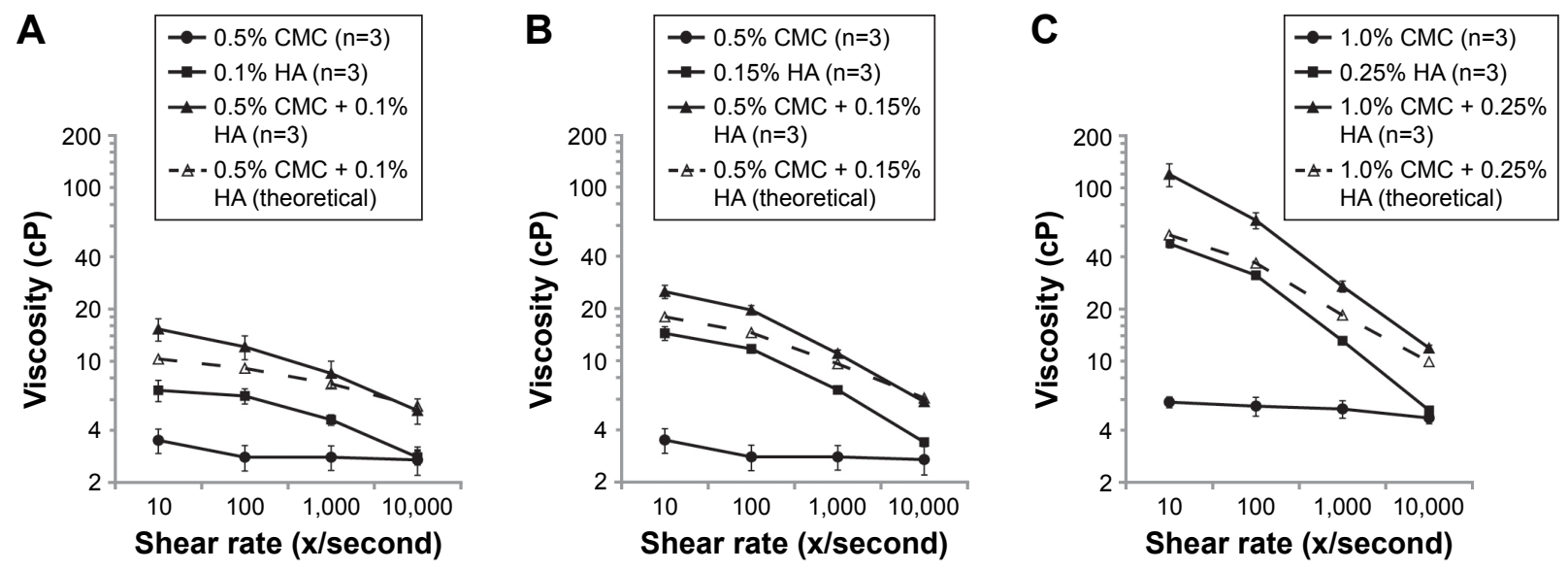

Figure 2 Rheological analysis of combinations of low (A), medium (B), and high (C) concentrations of CMC and HA polymers. Notes: Data points represent mean \pm standard deviation. Viscosity and shear rate are presented on a log scale. Abbreviations: CMC, carboxymethylcellulose; HA, hyaluronic acid.

and HA consistently demonstrated higher viscosity (observed values) than predicted by additive effects (theoretical values) in the 10-10,000/second shear rate range. The effect was greatest at lower levels of shear force, and decreased at higher levels. For example, the combination of $0.5 \% \mathrm{CMC}$ and $0.1 \%$ HA had observed viscosity of $15.3 \mathrm{cP}$ at $10 /$ second, which is $48 \%$ higher than the sum of the individual polymer viscosities.

Bulk viscosity measurements on the Brookfield viscometer confirmed that the viscosity of the combined solution (observed) was substantially higher than predicted (theoretical) by the sum of the individual solution viscosities. The measured value (SD) of the $0.5 \%$ CMC $-0.1 \%$ HA combination was 13.1 (1.9) cP, compared with the predicted value of $8.2 \mathrm{cP}$, representing a $60 \%$ increase (Figure 3).

Additional results obtained at the approximate temperature of the tear film (ie, $35^{\circ} \mathrm{C}$ ) revealed similar properties of the combined solution at $35^{\circ} \mathrm{C}$ and $25^{\circ} \mathrm{C}$, despite a slight reduction in absolute viscosity values.

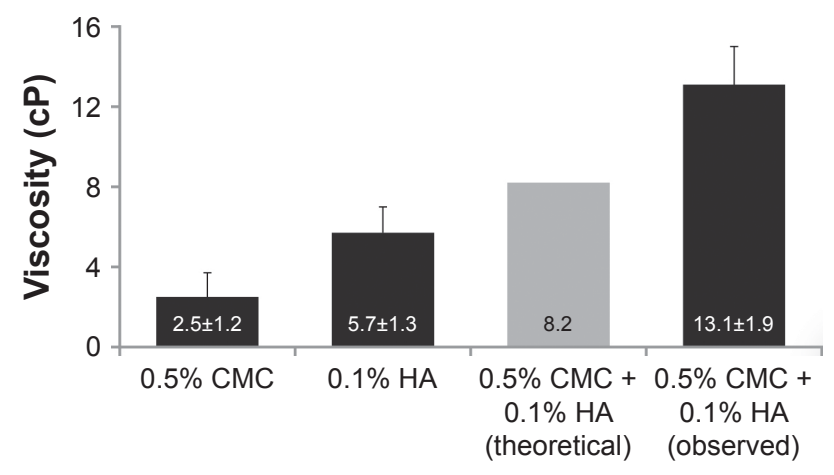

Figure 3 Bulk viscosity of the combined solution of $0.5 \% \mathrm{CMC}$ and $0.1 \% \mathrm{HA}$ was higher than predicted by additive effects.

Note: Data represent mean \pm standard deviation Brookfield viscosity at $60 \mathrm{rpm}$ (approximately equivalent to 79.2 /second).

Abbreviations: CMC, carboxymethylcellulose; HA, hyaluronic acid.

\section{Discussion}

Consistent with published reports, rheological testing showed that, individually, CMC and HA (in their native form, not cross-linked or chemically modified) exhibit viscoelastic properties that are affected by total polymer concentration and relative shear force. ${ }^{28,29}$ In comparison, observed results were higher than expected from additive effects when testing solutions combining CMC and HA. Indeed, rheological findings indicated that this combination of polymers exhibited higher viscosity than predicted from the sum of their individual formulation values, except at the highest shear rate tested (10,000/second), suggesting a synergistic effect, or cooperative interactions, between CMC and HA. This synergy at low shear force could potentially be explained (at least in part) by the fact that the relationship between viscosity and concentration is typically logarithmic, rather than additive, ${ }^{30}$ but cannot be fully explained by simple molecule entanglement because the increase in low-shear viscosity occurs immediately upon mixing $\mathrm{CMC}$ and $\mathrm{HA}$ polymers and is readily reversible (data not shown). Both $\mathrm{CMC}$ and $\mathrm{HA}$ are anionic at physiological $\mathrm{pH}$, exposing multiple hydroxyl and carboxyl water-binding sites that create a net negative charge and generate intra/interchain repulsion, thereby reducing chain-chain binding. It is this electrorepulsion that limits interactions between HA and CMC molecules to weaker, nonionic, fully reversible forces.

While the high molecular weight HA polymer $(>1,000 \mathrm{kDa})$ is predicted to form globular random coiled structures $^{31}$ (referred to as "time-average spheres") ${ }^{32}$ that include ions and small molecules but exclude macromolecules such as proteins, ${ }^{33}$ short/low molecular weight HA chains cannot coil and remain somewhat extended and flexible in aqueous solution. ${ }^{31}$ Similarly, the CMC polymer is 
not known to coil and is mostly linear/extended in solution. ${ }^{34}$ In both cases, extension occurs because electrorepulsion at adjacent anionic sites increases as the backbone bends, causing chain rigidity. It is also worth noting that the CMC polymer used in this study was significantly shorter/smaller (approximately 30 times) than the HA polymer. With a CMC:HA weight ratio of $5: 1$, the CMC:HA molar ratio was $>100: 1$. Nonetheless, CMC is largely excluded from HA spheres (due to its relatively large size compared with water and ions), which likely contributes to the macromolecular interactions between the two anionic polymers and forms the basis for the observed rheological synergy.

Solutes cannot occupy the same space at the same time, and their associated hydration shells may not only control a larger volume than the size of the solute itself but also behave differently than the bulk solution. ${ }^{35}$ In this "bridged matrix" model, spheres composed of individual HA molecules occupy a greater volume because of their shape and total hydration space, explaining why (at least in part) HA is responsible for the majority of the solution viscosity in the $\mathrm{CMC}-\mathrm{HA}$ combination, despite the greater amount of $\mathrm{CMC}$ by weight and total number of molecules. These HA spheres allow relatively free movement of water, ions, and small molecules, yet exclude $\mathrm{CMC}$, owing to its size and anionic repulsion forces. ${ }^{33,34,36}$ The partitioning of HA and CMC molecules, occurring to a greater degree than predicted under conditions of low shear (ie, "at rest"), may thus explain the unexpected rheological properties of the CMC-HA combination. High molecular weight HA will swell and occupy nearly all available volume at $0.1 \%$, the concentration at which HA-HA entanglement has been reported. ${ }^{37}$ If CMC is excluded from the HA spheres, its concentration in the available space will be increased, ${ }^{35}$ and given that HA and $\mathrm{CMC}$ are both negatively charged, any entanglement that occurs will be limited and reversible, despite the proximity of the molecules. In this model, the excluded CMC molecules residing around the HA spheres (more so at rest) provide a stiffening component to the mixture by bridging physical forces between adjacent HA molecules. ${ }^{38}$ Under conditions of high shear force, compression and elongation of HA are expected to occur, and CMC-HA entanglement/weak binding would be broken as a consequence.

The effectiveness of the CMC-HA combination at $0.5 \% / 0.1 \%$ concentrations (Optive Fusion; Allergan plc, Dublin, Ireland) has been reported recently in two multicenter, randomized clinical trials involving patients with mild to severe dry eye. ${ }^{39,40}$ The effects of this combination on dry eye symptoms that develop after cataract surgery have also been investigated in a randomized study. ${ }^{41}$ Moreover, preservative-free and multidose preserved formulations with this combination of polymers have now become available. In these formulations, the salt content is significantly lower than in the majority of HA-based products. Osmotic balance is achieved by using organic osmolytes or other compatible solutes, without addition of sodium chloride. ${ }^{29,42}$ The reduction/absence of $\mathrm{Na}^{+}$ions in solution increases the availability of anionic binding sites that attract and hold water, further increasing the hydration sphere around the CMC and HA polymer chains and, consequently, increasing viscosity and delivering water to the ocular surface. ${ }^{29,42}$ Increased viscosity at low shear, such as exists between blinks, should improve retention of each eyedrop instilled in the eye and thus optimize hydration and protection of the ocular surface. On the other hand, reduced viscosity at high shear, such as occurs during blinking, should improve ocular comfort and reduce symptoms of stickiness and blur associated with some eyedrop formulations. Whether formulations such as CMC 1.0\% + HA $0.25 \%$ may be too concentrated for therapeutic use or better suited for nighttime treatment (when blurred vision is not a concern) remains to be determined. Overall, however, the CMC-HA combination of polymers does produce a synergistic effect that enhances its low-shear viscosity above what would be expected, allowing for greater retention on the ocular surface without increasing the total concentration of the polymers. Above a certain point, the increase in low-shear viscosity does lead to less desirable effects, as previously shown, ${ }^{39}$ and the more viscous product does not perform as well for a broad range of dry eye patients. Therefore, an optimum formulation of the combination of CMC and HA should consider the resultant viscosity and the target patient population.

\section{Acknowledgments}

We would like to posthumously recognize Bereth J Beard, BSc for her efforts and contributions to the conduct of this study and development of the first draft of this manuscript. This study was sponsored by Allergan plc, Irvine, CA, USA. Writing and editorial assistance was provided to the authors by Michele Jacob, PhD, CMPP of Evidence Scientific, Philadelphia, PA, USA, and funded by Allergan plc. All authors met the ICMJE authorship criteria.

\section{Disclosure}

PAS and JGV are employees of Allergan plc and report no other conflicts of interest in this work. 


\section{References}

1. American Academy of Ophthalmology. Preferred Practice Pattern: Dry Eye Syndrome. San Francisco: AAO; 2013.

2. [No authors listed]. The epidemiology of dry eye disease: report of the Epidemiology Subcommittee of the International Dry Eye WorkShop (2007). Ocul Surf. 2007;5(2):93-107.

3. [No authors listed]. Expert consensus in the treatment of dry eye inflammation. Ophthalmol Times. 2007;32(7):1-12.

4. Behrens A, Doyle JJ, Stern L, et al. Dysfunctional tear syndrome: a Delphi approach to treatment recommendations. Cornea. 2006;25(8): 900-907.

5. Aragona P, Papa V, Micali A, Santocono M, Milazzo G. Long term treatment with sodium hyaluronate-containing artificial tears reduces ocular surface damage in patients with dry eye. Br J Ophthalmol. 2002; 86(2):181-184.

6. US Food and Drug Administration. Ophthalmic Demulcents. Washington: US Government Printing Office; 2000.

7. Lenton LM, Albietz JM. Effect of carmellose-based artificial tears on the ocular surface in eyes after laser in situ keratomileusis. J Refract Surg. 1999;15(2 Suppl):S227-S231.

8. Grene RB, Lankston P, Mordaunt J, Harrold M, Gwon A, Jones R. Unpreserved carboxymethylcellulose artificial tears evaluated in patients with keratoconjunctivitis sicca. Cornea. 1992;11(4):294-301.

9. Baudouin C, Cochener B, Pisella PJ, et al. Randomized, phase III study comparing osmoprotective carboxymethylcellulose with sodium hyaluronate in dry eye disease. Eur J Ophthalmol. 2012;22(5): 751-761.

10. Monaco G, Cacioppo V, Consonni D, Troiano P. Effects of osmoprotection on symptoms, ocular surface damage, and tear film modifications caused by glaucoma therapy. Eur J Ophthalmol. 2011;21(3): 243-250.

11. Garrett Q, Xu S, Simmons PA, et al. Carboxymethyl cellulose stimulates rabbit corneal epithelial wound healing. Curr Eye Res. 2008;33(7): 567-573.

12. Garrett Q, Simmons PA, Xu S, et al. Carboxymethylcellulose binds to human corneal epithelial cells and is a modulator of corneal epithelial wound healing. Invest Ophthalmol Vis Sci. 2007;48(4):1559-1567.

13. Simmons PA, Vehige JG. Clinical performance of a mid-viscosity artificial tear for dry eye treatment. Cornea. 2007;26(3):294-302.

14. Noecker RJ. Comparison of initial treatment response to two enhancedviscosity artificial tears. Eye Contact Lens. 2006;32(3):148-152.

15. Nilforoushan MR, Latkany RA, Speaker MG. Effect of artificial tears on visual acuity. Am J Ophthalmol. 2005;140(5):830-835.

16. Albietz JM, Lenton LM, McLennan SG, Earl ML. A comparison of the effect of Refresh Plus and Bion tears on dry eye symptoms and ocular surface health in myopic LASIK patients. CLAOJ. 2002;28(2): 96-100.

17. Diebold Y, Herreras JM, Callejo S, Argueso P, Calonge M. Carbomerversus cellulose-based artificial-tear formulations: morphologic and toxicologic effects on a corneal cell line. Cornea. 1998;17(4):433-440.

18. Baeyens V, Bron A, Baudouin C. Efficacy of $0.18 \%$ hypotonic sodium hyaluronate ophthalmic solution in the treatment of signs and symptoms of dry eye disease. J Fr Ophtalmol. 2012;35(6):412-419.

19. Lee JH, Ahn HS, Kim EK, Kim TI. Efficacy of sodium hyaluronate and carboxymethylcellulose in treating mild to moderate dry eye disease. Cornea. 2011;30(2):175-179.

20. Vogel R, Crockett RS, Oden N, Laliberte TW, Molina L. Demonstration of efficacy in the treatment of dry eye disease with $0.18 \%$ sodium hyaluronate ophthalmic solution (Vismed, Rejena). Am J Ophthalmol. 2010;149(4):594-601.

21. Troiano P, Monaco G. Effect of hypotonic $0.4 \%$ hyaluronic acid drops in dry eye patients: a cross-over study. Cornea. 2008;27(10): 1126-1130.
22. Johnson ME, Murphy PJ, Boulton M. Effectiveness of sodium hyaluronate eyedrops in the treatment of dry eye. Graefes Arch Clin Exp Ophthalmol. 2006;244(1):109-112.

23. Gomes JA, Amankwah R, Powell-Richards A, Dua HS. Sodium hyaluronate (hyaluronic acid) promotes migration of human corneal epithelial cells in vitro. Br J Ophthalmol. 2004;88(6):821-825.

24. Condon PI, McEwen CG, Wright M, Mackintosh G, Prescott RJ, McDonald C. Double blind, randomised, placebo controlled, crossover, multicentre study to determine the efficacy of a $0.1 \%(\mathrm{w} / \mathrm{v})$ sodium hyaluronate solution (Fermavisc) in the treatment of dry eye syndrome. Br J Ophthalmol. 1999;83(10):1121-1124.

25. Yokoi N, Komuro A, Nishida K, Kinoshita S. Effectiveness of hyaluronan on corneal epithelial barrier function in dry eye. Br J Ophthalmol. 1997;81(7):533-536.

26. Snibson GR, Greaves JL, Soper ND, Prydal JI, Wilson CG, Bron AJ. Precorneal residence times of sodium hyaluronate solutions studied by quantitative gamma scintigraphy. Eye (Lond). 1990;4(Pt 4):594-602.

27. DeLuise VP, Peterson WS. The use of topical Healon tears in the management of refractory dry-eye syndrome. Ann Ophthalmol. 1984; 16(9):823-824.

28. Benchabane A, Bekkour K. Rheological properties of carboxymethyl cellulose (CMC) solutions. Colloid Polym Sci. 2008;286(10): $1173-1180$.

29. Kobayashi Y, Okamoto A, Nishinari K. Viscoelasticity of hyaluronic acid with different molecular weights. Biorheology. 1994;31(3):235-244.

30. Thomas DK, Thomas TAJ. Viscosity-concentration relationships in solutions of high polymers. J Appl Polym Sci. 1960;3(8):129-131.

31. Cowman MK, Matsuoka S. Experimental approaches to hyaluronan structure. Carbohydr Res. 2005;340(5):791-809.

32. Cowman MK, Schmidt TA, Raghavan P, Stecco A. Viscoelastic properties of hyaluronan in physiological conditions. F1000Res. 2015;4:622.

33. Fraser JR, Laurent TC, Laurent UB. Hyaluronan: its nature, distribution, functions and turnover. J Intern Med. 1997;242(1):27-33.

34. Chytil M, Lišková K, Janeček J. The influence of counterions of different valency on carboxymethylcellulose viscoelastic behavior. In: Mitchell G, editor. Rheology: Theory, Properties and Practical Applications. 1st ed. Hauppauge (NY): Nova Science Publishers; 2014.

35. Murphy LR, Matubayasi N, Payne VA, Levy RM. Protein hydration and unfolding - insights from experimental partial specific volumes and unfolded protein models. Fold Des. 1998;3(2):105-118.

36. Guillaumie F, Furrer P, Felt-Baeyens O, et al. Comparative studies of various hyaluronic acids produced by microbial fermentation for potential topical ophthalmic applications. J Biomed Mater Res A. 2010;92A(4): 1421-1430.

37. Becker LC, Bergfeld WF, Belsito DV, et al. Final report of the safety assessment of hyaluronic acid, potassium hyaluronate, and sodium hyaluronate. Int J Toxicol. 2009;28(4 Suppl):5-67.

38. Ellis RJ. Macromolecular crowding: obvious but underappreciated. Trends Biochem Sci. 2001;26(10):597-604.

39. Simmons PA, Liu H, Carlisle-Wilcox C, Vehige JG. Efficacy and safety of two new formulations of artificial tears in subjects with dry eye disease: a 3-month, multicenter, active-controlled, randomized trial. Clin Ophthalmol. 2015;9:665-675.

40. Labetoulle M, Chiambaretta F, Shirlaw A, Leaback R, Baudouin C. Osmoprotectants, carboxymethylcellulose and hyaluronic acid multiingredient eye drop: a randomised controlled trial in moderate to severe dry eye. Eye (Lond). Epub 2017 Apr 28.

41. Mencucci R, Boccalini C, Caputo R, Favuzza E. Effect of a hyaluronic acid and carboxymethylcellulose ophthalmic solution on ocular comfort and tear-film instability after cataract surgery. $J$ Cataract Refract Surg. 2015;41(8):1699-1704.

42. Gribbon P, Heng BC, Hardingham TE. The molecular basis of the solution properties of hyaluronan investigated by confocal fluorescence recovery after photobleaching. Biophys J. 1999;77(4):2210-2216. 


\section{Publish your work in this journal}

Clinical Ophthalmology is an international, peer-reviewed journal covering all subspecialties within ophthalmology. Key topics include: Optometry; Visual science; Pharmacology and drug therapy in eye diseases; Basic Sciences; Primary and Secondary eye care; Patient Safety and Quality of Care Improvements. This journal is indexed on

Submit your manuscript here: http://www.dovepress.com/clinical-ophthalmology-journal
PubMed Central and CAS, and is the official journal of The Society of Clinical Ophthalmology (SCO). The manuscript management system is completely online and includes a very quick and fair peer-review system, which is all easy to use. Visit http://www.dovepress.com/ testimonials.php to read real quotes from published authors. 